\title{
A dromaeosaur from the Maastrichtian of James Ross Island and the Late Cretaceous Antarctic dinosaur fauna
}

\author{
Judd A. Case, ${ }^{1}$ James E. Martin, ${ }^{2}$ and Marcelo Reguero ${ }^{3}$ \\ ${ }^{1}$ College of Science, Eastern Washington University, Cheney, WA 99004 USA (jcase@mail.ewu.edu) \\ ${ }^{2}$ Museum of Geology, South Dakota School of Mines \& Technology, Rapid City, SD 57701 USA (James.Martin@sdsmt.edu) \\ ${ }^{3}$ Departmento Paleontologia de Vertebrados, Museo de La Plata, 1Paseo del Bosque 1990 La Plata, Argentina (mreguero@netverk.com.ar)
}

\begin{abstract}
The recovery of material of a small theropod from the Early Maastrichtian, Cape Lamb Member of the Snow Hill Island Formation is an unusual occurrence from primarily marine sediments. The pedal morphology of the specimen that includes a Metatarsal II with a lateral expansion caudal to Metatarsal III, a third metatarsal that is proximally narrow and distally wide, a Metatarsal III with a distal end that is incipiently ginglymoidal and a second pedal digit with sickle-like ungual are all diagnostic of a theropod that belongs to the family of predatory dinosaurs, the Dromaeosauridae. Yet this Antarctic dromaeosaur retains plesiomorphic features in its ankle and foot morphology. As new dromaeosaur species are being recovered from the mid-Cretaceous of South America and the retention of primitive characters in the Antarctic dromaeosaur, a new biogeographic hypothesis on dromaeosaur distribution has been generated. Gondwanan dromaeosaurs are not North America immigrants into South America and Antarctica; rather they are the relicts of a cosmopolitan dromaeosaur distribution, which has been separated by the vicariant break up of Pangea and created an endemic clade of dromaeosaurs in Gondwana.

Citation: Case, J.A., J.E. Martin, and M. Reguero (2007), A dromaeosaur from the Maastrichtian of James Ross Island and the Late Cretaceous Antarctic dinosaur fauna, in Antarctica: A Keystone in a Changing World - Online Proceedings of the $10^{\text {th }}$ ISAES X, edited by A.K. Cooper and C.R. Raymond et al., USGS Open-File Report 2007-1047, Short Research Paper 083, 4 p.; doi:10.3133/of2007-1047.srp083
\end{abstract}

\section{Introduction}

Relatively few dinosaurs have been collected from the Late Cretaceous of Antarctica. Heretofore, only five dinosaur species have been reported from the James Ross Basin on the eastern side of the Antarctic Peninsula (Figure 1).

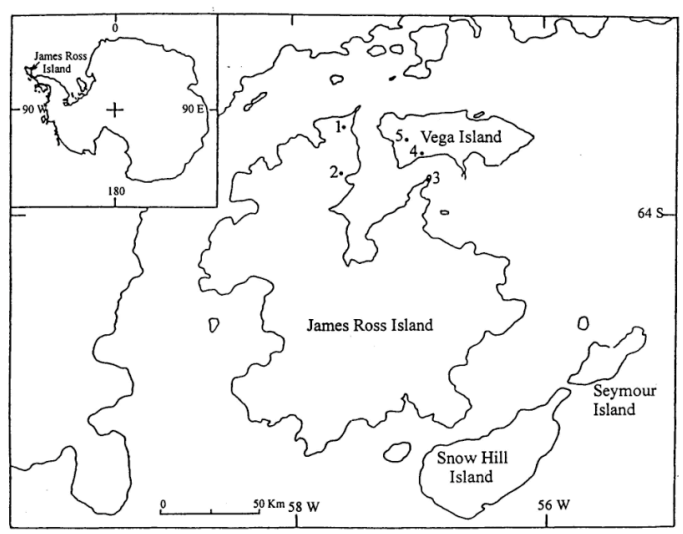

Figure 1. James Ross Basin along the northeastern Antarctic Peninsula. The numbered localities indicate where dinosaur specimens have been recovered: 1) Cape Lachman, a large theropod; 2) Santa Marta Cove, a nodosaur; 3) The Naze, an iguantodontid and the dromaeosaur reported here; 4) Cape Lamb, a hypsilophodontid; and 5) Sandwich Bluff, a hadrosaur.

The principal reason for the paucity of dinosaurs is because the source rocks were deposited in a shallow marine environment. Therefore, any specimens recovered represent specimens that had to have been derived from terrestrial environments and floated from shore, to be preserved against high odds in a marine setting.
Discovery of associated dinosaur remains are rare in such circumstances, making the recovery reported herein unusual.

The associated remains of a small theropod dinosaur weathered from the lower portion of the Cape Lamb Member of the Snow Hill Island Formation (Crame et al., 2004) on the Naze of James Ross Island. This new dinosaur occurrence is the second theropod from the Late Cretaceous of Antarctica. The first is a large megalasaurlike theropod represented by a femur from Santonian rocks in Cape Lachman, James Ross Island (Molnar et al., 1996). This femur represents a very large theropod species, much larger than the gracile theropod discussed here. Other dinosaur remains include a nodosaur, the first dinosaur recovered from Late Cretaceous rocks in Antarctica (Gasparini et al., 1987). The nodosaur was recovered from Santa Marta Cove area on James Ross Island from the Late Campanian Herbert Sound Member of the Santa Marta Formation (Crame et al., 1991). From the younger Cape Lamb Member of the Snow Hill Island Formation on Vega Island, a partial skeleton of a hysilophodontid dinosaur was recovered from these Early Maastrichtian deposits (Hooker et al. 1992). From similar-aged deposits on the James Ross Island, portions of a hindleg and foot of an iguanodontid were recovered (Cambiaso et al., 2002). However its exact stratigraphic and geographic location are unsure, although field evidence suggests that it came from Fortress Hill next to Terrapin Hill. Finally, dental and pedal material of a hadrosaurine hadrosaur, was recovered from the Late Maastrichtian Sandwich Bluff Member of the Snow Hill Island Formation on Vega Island (Case et al., 2000). As can be observed, most specimens are fragmentary in nature, so the recovery of an associated series of skeletal 


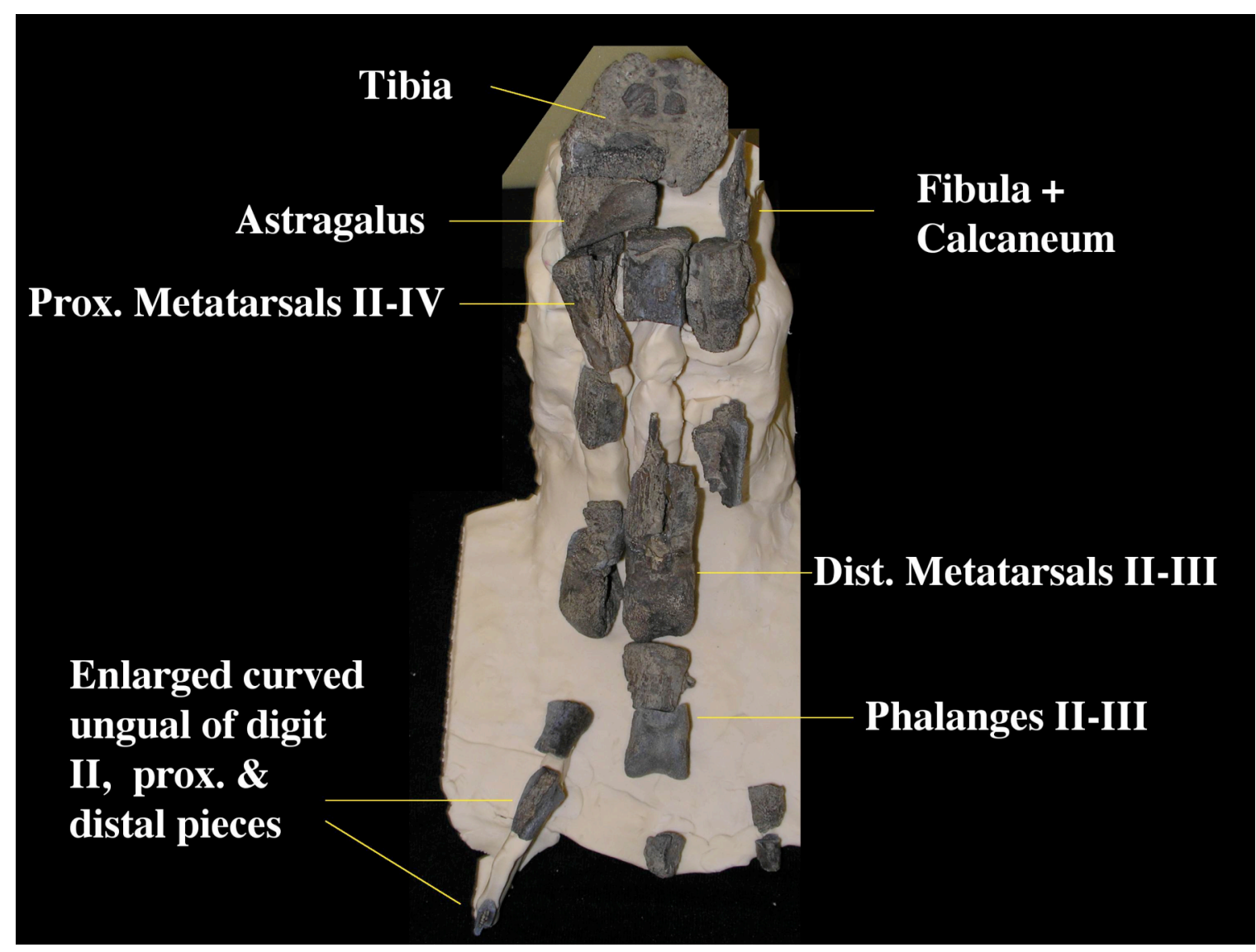

Figure 2. Posing of the bones in life position of the left lower leg, ankle and foot of the dromaeosaur from the Naze Peninsula on James Ross Island. In addition to the bones from the left hindlimb illustrated here, the specimen also includes some elements from the right hindlimb including distal tibia, and distal ends of metatarsals II and III.

elements belonging to a carnivorous dinosaur is most fortuitous.

\section{Description}

The dentition is poorly preserved except for two teeth that were preserved in a fragment of concretion. The teeth and the associated fragments all indicate long, narrow biconvex teeth. This shape suggests that both anterior and posterior carina were present; however, no serrations were noted on the carina, thus it is impossible to determine if serrations were present or absent. The teeth are incipiently laterally compressed, but retain a rounded outline, particularly anteriorly. The shape is indicative of teeth from the anterior region of the jaw.

The left tibia is the most complete of the two tibia fragments and most of the pedal elements are from the left pes as well. The distal articular surface of the tibia is planar and pentagonal in outline. The anterior face of the distal tibia is only slightly concave to indicate the point of articulation with the ascending process of the astragalus. The astragalus is spool shaped with a thick semicircular medial end and a thinner lateral end. The distal astragular facet is curved from the anterior side to the posterior side. The anterior surface is vertical, forming the base of the ascending process of the astragalus. The ascending process is broken at $1.1 \mathrm{~cm}$ above its base. The tibia is locked into the astragalus with the planar tibioastragalar facet and with the ascending process of the astragalus, but the normally tight articulation between the ascending process and the tibia seen in theropods is absent here. The disc-shaped calcaneus is separate from the astragalus, however, the calcaneus is fused to the fibula. The calcaneus articulates with the Metatarsal IV (= MtIV) and the distal fibula is ovoid in cross-section.

The proximal and distal ends of metatarsals II, III, and IV are present for the left pes. The diaphyses for the metatarsal have been highly fragmented by the freezing and thawing conditions of the Antarctic climate and so far only partial reconstruction of the diaphyses have been possible. The proximal articular surface of MtII is concave dorsally to accommodate the thick and curved medial end of the astragalus. The distal MtII is condylar in medial view, but triangular in ventral view. The distal articular surface is narrow anteriorly and wide posteriorly, 
as it forms a grooved and bitrochlear articular surface, thus anteriorly the distal articular surface is convex while posteriorly it is ginglymoidal.

MtIII retains a flattened distal tarsal element. This outline in dorsal view of the proximal end of Mt III is bullet-shaped with the sides being both convex. Posteriorly, the MtIII is pinched into a long narrow ridge resulting in the triangular cross-section for most of the length of the diaphysis. MtII and MtIV are also triangular in cross-section however in each case the apex is directed towards the central metatarsal (MtIII). The triangular shape is the result of a posterolateral expansion in MtII and a posteromedial expansion in MtIV. These expansions or flanges thus obscure much of the length of MtIII in posterior view so that only the narrow posterior ridge on MtIII can be seen. The distal end is wide and ginglymoidal with prominent medial and lateral trochlea bordering a wide sulcus.

The MtIV outline is an ovoid and the distal end of MtIV resembles that of the distal end of MtII. The first phalanx of digit II is large and tall as the proximal articular surface is extended vertically. The articular surface is not ginglymoidal, but it is highly cupped, extended and asymmetrical to match the shape of the distal articular surface of MtII. The ungual phalanx of digit II is enlarged and trenchant, but the element is incomplete with only the proximal third and a fragment near the tip recovered. Here the proximal articular surface is keeled and thus ginglymoidal. The lateral groove is more dorsal than the medial groove and remains the deeper of the two near to the tip of the ungual. The distal portion of the ungual is tall and narrow and symmetrical in cross-section.

\section{Discussion}

\section{Morphology}

The morphology of the pes is consistent with that of members of the theropod family Dromaeosauridae, a family that includes such predatory dinosaurs as Velociraptor and Deinonychus, which have an enlarged sickle-like claw on their hindfeet. Novas and Pol (2005) presented a suite of diagnostic character states for the pes of a dromaeosaurid, which are also present in this Antarctic specimen: Mt II with a lateral expansion caudal to Mt III; Mt III proximally narrow distally wide; distal end of Mt III is incipiently ginglymoidal; pedal digit II with trenchant ungual phalanx. These diagnostic features clearly indicate that the theropod specimen from the Naze on James Ross Island, is a dromaeosaur. However, the Naze dromaeosaur is much less derived than dromaeosaurs or the sister family Troodontidae of a similar Late Cretaceous age from Laurasia, in that the metatarsals are not long and slender and thus, generally being longer than the length of the phalanges on digit III. The metatarsal length may also be a function of size, but Achillobatar, which is similar in size to the Naze dromaeosaur also has elongate metatarsals. Two additional plesiomorphic features of the Naze dromaeosaur are the juxtaposition of the ascending process of the astragalus and the anterior distal tibia without a well-defined fossa on the tibia and the incipient ginglymoidal MtII/digit II joint. Thus in many ways, the Naze dromaeosaur more closely resembles Early Cretaceous dromaeosaurs such as Deinonychus and Utahraptor rather than contemporaneous dromaeosaurids, Velociraptor and Dromaeosaurus or regional close (i.e. South American) species like Neuquenraptor (Novas and Pol, 2005) or Buitreraptor (Makovichy et al., 2005).

\section{Biogeography}

Dromaeosaurids were originally thought to have originated in North America in the Early Cretaceous (Barremian), dispersed to Asia and then into Europe (Ostrom, 1990). The Asian record now extends back to the Barremian (Xu et al., 2000) and the two new South American (Gondwanan) species have now been recorded from earlier time frames of Cenomanian and Coniacian ages (Makovichy et al., 2005; Novas and Pol, 2005 respectively). By the middle of the Cretaceous, dromaeosaurs are in Asia, North America and South America. The plesiomorphic nature of the ankle and pes of the Naze dromaeosaur is supportive of a hypothesis that dromaeosaurs were in fact cosmopolitan in their distribution and then fragmented vicariously into a Gondwanan clade that was separate from the Laurasian radiation (Makovichy et al., 2005; Novas and Pol, 2005). Consequently, the Naze dromaeosaur may in fact be a latest Cretaceous remnant of the Early Cretaceous, cosmopolitan, basal stock of dromaeosaurids.

The majority of the dinosaur assemblage from the Antarctic Peninsula (the megalasaur-like theropod, the nodosaur, the iguanodontid and the hypsilophodontid) are remnants of a cosmopolitan dinosaur fauna more typical of other areas at earlier times (e.g. mid-Cretaceous of North America and Australia; Case et al., 2003). The recovery of a dromaeosaur from the Maastrichtian of Antarctica up until recently would have been viewed in much the same way as the hadrosaur is viewed, that is as a North American immigrant into the Antarctic region. However, the occurrences of dromaeosaurs in the midCretaceous of South America and the retention of plesiomorphic characters in the Naze dromaeosaur tell a different biogeographic tale. Rather, the dromaeosaurs, like most of the Antarctic Peninsula dinosaur fauna, is a relict of a cosmopolitan dinosaur distribution that is still present in Antarctica until the end of the "Age of Dinosaurs" at the end of the Cretaceous.

Acknowledgements. This work was supported by The National Science Foundation Office of Polar Programs grants 0003844 (to J. Case) and 0087972 (to J. Martin). Additionally, we would like to thank Raytheon Polar Services for their logistical support for this project with special thanks to Melissa Rider and John Evans. We would like to thank Captain Mike Terminal and the crew of the RS Laurence M. Gould for getting us there and getting us back. 


\section{References}

Cambiaso, A., Novas, F., Lirio, J.M., and Nunez, H. 2002. Un Nuevo dinosaurio ornithopodo del Cretacio Superior de la Isla James Ross, Peninsula Antartica. VIII Congresso Argentino de Paleontologia y Bioestratigrafia, Resumenes, p.61.

Case, J.A., J.E. Martin, D.S. Chaney, M. Reguero, S.A. Marenssi, S.M. Santillana and M.O. Woodburne. 2000. The first duck-billed dinosaur (Hadrosauridae) from Antarctica. Journal of Vertebrate Paleontology 20(3):612-614.

Case, J.A., J.E. Martin, D.S. Chaney and M. Reguero. 2003 Late Cretaceous Dinosaurs from the Antarctic Peninsula: Remnant or Immigrant Fauna? Journal of Vertebrate Paleontology 23(3 supplement):39A.

Crame, J.A., D. Pirrie, J.B. Riding, M.R.A. Thomson. 1991. Campanian-Maastrichtian (Cretaceous) stratigraphy of the James Ross Island area, Antarctica. Journal of the Geological Society, London 148:1125-1140.

Crame, J. A., J. E. Francis, D. J. Cantrill, and D. Pirrie. 2004. Maastrichtian stratigraphy of Antarctica. Cretaceous Research 25: 411-423.
Gasparini, Z., E. Olivero, R. Scasso and C. Rinaldi. 1987. Un ankylosaurio (Reptila, Ornithischia) campaniano en el continente antartico. Anias IV Congresso Brasileiro de Paleontologia, Rio de Janeiro 1:131-141.

Hooker, J.J., A.C. Milne, and S. Sequira. 1992. An ornithopod dinosaur from the Late Cretaceous of West Antarctica. Antarctic Science 3:331-332.

Makovichy, P.J., S. Apesteguia and F.L. Agnolin. 2005. The earliest dromaeosaurid theropod from South America. Nature 437:10071011.

Molnar, R.E., L.A. Angriman and Z. Gasparini. 1996. An Antarctic Cretaceous theropod. Memoirs of the Queensland Museum 39(3):669-674.

Novas, F.E. and D. Pol 2005. New evidence on deinonychosaurian dinosaurs from the Late Cretaceous of Patagonia. Nature 433:858861.

Ostrom, J.H. 1990. Dromaeosauridae. In D.B. Weishampel, P. Dodson and H. Osmolska (eds.), The Dinosauria. University of Claifornia Press, Berkeley, p. 269-279.

$\mathrm{Xu}, \mathrm{X}$., Z. Zhou and X. Wang. 2000. The smallest known non-avian theropod dinosaur. Nature 408:705-708. 